\title{
Curcumin potentiates the fungicidal effect of dodecanol by inhibiting drug efflux in wild-type budding yeast
}

\author{
C. Yamawaki, M. Oyama, Y. Yamaguchi, A. Ogita, T. Tanaka, K.-I. Fujita
}

\begin{tabular}{|c|l|}
\hline Citation & Letters in Applied Microbiology, 68(1); 17-23 \\
\hline Issue Date & $2019-01$ \\
\hline Type & Journal Article \\
\hline Textversion & author \\
\hline \multirow{2}{*}{ Rights } & $\begin{array}{l}\text { This is the peer reviewed version of the following article: YAMAWAKI C, OYAMA M, } \\
\text { YAMAGUCHI Y, OGITAA, TANAKA T, \& FUJITA KI. (2018). Letters in Applied } \\
\text { Microbiology. Vol.68, Issue.1, p.17-23, which has been published in final form at } \\
\text { https:/doi.org/10.1111/lam.13083. } \\
\text { This article may be used for non-commercial purposes in accordance with Wiley Terms } \\
\text { and Conditions for Self-Archiving. }\end{array}$ \\
\hline DOI & \begin{tabular}{l}
$10.1111 / l a m .13083$ \\
\hline
\end{tabular}
\end{tabular}

\author{
Self-Archiving by Author(s) \\ Placed on: Osaka City University
}

YAMAWAKI C, OYAMA M, YAMAGUCHI Y, OGITA A, TANAKA T, \& FUJITA KI. (2018). Curcumin potentiates the fungicidal effect of dodecanol by inhibiting drug efflux in wild-type budding yeast. Letters in Applied Microbiology. 68, 17-23. doi:10.1111/lam.13083 
1 Curcumin potentiates the fungicidal effect of dodecanol by inhibiting drug efflux

2 in wild-type budding yeast

3

4 Chika Yamawaki ${ }^{1}$, Masahiro Oyama ${ }^{1}$, YoshihiroYamaguchi ${ }^{1,2}$, Akira Ogita ${ }^{1,3}$, Toshio

$5 \quad$ Tanaka $^{1}$, Ken-ichi Fujita ${ }^{1, *}$

6

$7 \quad{ }^{1}$ Graduate School of Science, Osaka City University, Sumiyoshi-ku, Osaka, Japan

$8{ }^{2}$ Advanced Research Institute for Natural Science and Technology, Osaka City

9 University, Sumiyoshi-ku, Osaka, Japan

$10{ }^{3}$ Research Center for Urban Health and Sports, Osaka City University, Sumiyoshi-ku,

11 Osaka, Japan

12

$13 *$ Correspondence

14 Ken-ichi Fujita

15 E-mail address: kfujita@sci.osaka-cu.ac.jp; Phone: +81-6-6605-2580

16

17 Running headline: Curcumin inhibits drug efflux 


\section{Significance and Impact of the Study:}

19 Drug resistance is common in immunocompromised patients with fungal infections.

20 Curcumin, isolated from Curcuma longa, inhibits drug efflux in non-pathogenic budding

21 yeast Saccharomyces cerevisiae cells overexpressing ABC transporters $S$. cerevisiae

22 Pdr5p and pathogenic Candida albicans Cdr1p and Cdr2p. We examined the effects of

23 curcumin on multidrug resistance in a wild-type strain of the budding yeast with an

24 intrinsic expression system of multidrug-efflux-related genes. Curcumin directly

25 inhibited drug efflux and also suppressed $P D R 5$ expression, thereby enhancing antifungal

26 effects. Thus, curcumin potentially promotes the efficacy of antifungals via its effects on

$27 \quad \mathrm{ABC}$ transporters in wild-type fungal strains.

29 Abstract

30 Drug resistance commonly occurs when treating immunocompromised patients who have

31 fungal infections. Curcumin is a compound isolated from Curcuma longa. It has been reported to inhibit drug efflux in several human cell lines and non-pathogenic budding

33 yeast Saccharomyces cerevisiae cells that overexpress the ATP-binding cassette 34 transporters $S$. cerevisiae Pdr5p and pathogenic Candida albicans Cdr1p and Cdr2p. The 
35 aim of this study was to examine the effects of curcumin on multidrug resistance in a

36 wild-type strain of the budding yeast with an intrinsic expression system of multidrug-

37 efflux-related genes. The antifungal activity of dodecanol alone was temporary against $S$.

38 cerevisiae; however, restoration of cell viability was completely inhibited when the cells

39 were co-treated with dodecanol and curcumin. Furthermore, restriction of rhodamine $6 \mathrm{G}$

40 (R6G) efflux from the cells and intracellular accumulation of R6G were observed with

41 curcumin treatment. Reverse transcription-polymerase chain reaction analysis revealed

42 that curcumin reduced dodecanol-induced overexpression of the ABC transporter-related

43 genes $P D R 1, P D R 3$, and $P D R 5$ to their control levels in untreated cells. Curcumin can

44 directly restrict glucose-induced drug efflux and inhibit the expression of the $\mathrm{ABC}$

45 transporter gene $P D R 5$, and can thereby probably inhibit the efflux of dodecanol from $S$.

46 cerevisiae cells. Curcumin is effective in potentiating the efficacy of antifungal drugs via

47 its effects on $\mathrm{ABC}$ transporters.

49 Keywords

50 Curcumin, antifungal, $S$. cerevisiae, $\mathrm{ABC}$ transporter, multidrug resistance 


\section{Introduction}

53 Immunocompromised patients usually develop deep-seated mycoses because of

54 opportunistic invasive fungal infections (Miceli et al. 2011). As fungi and humans are

55 eukaryotes, they are similar in cellular structure and metabolism. The primary targets of

56 antifungal drugs are ergosterol, the fungal cell wall, and cytosine deaminase.

57 Consequently, the efficacy of antifungal agents is limited due to their similar mechanisms

58 of action (Fairlamb et al. 2016). Therefore, it is difficult to develop antifungals with few

59 adverse effects and new modes of action.

61 azoles, which include fluconazole (Masiá Canuto and Gutiérrez Rodero 2002), and 5-

62 fluorocytosine (Polak and Hartman 1991). An opportunistic pathogenic Candida species

63 with lower susceptibility to echinocandins has been isolated from humans (Gonçalves et

64 al. 2016). Therefore, strategies for overcoming drug resistance should be developed to improve antifungal chemotherapy.

66 The mechanisms by which resistance occurs include enzymatic degradation or

67 modification of antifungals, inability of antifungals to bind targets sites due to mutation 
69 Rice 1999). Fungi can develop various multidrug efflux pumps, such as ATP-dependent

70 transporters (e.g., ATP-binding cassette (ABC) transporters), which transport drugs out

71 of the fungal cells (Cannon et al. 2009; Li and Nikaido 2009; Paul and Moye-Rowley

72 2014). trans-Anethole is a phenylpropanoid (Fig. 1) and a principal constituent of

74 anise oil. It shows a synergistic antifungal effect against the budding yeast

75 Saccharomyces cerevisiae in combination with other antifungal agents by inhibiting the

76 gene expression of multidrug efflux pumps, mainly the ABC transporter Pdr5p (Fujita et

77 al. 2017). In a preliminary structure-activity relationship study on synergistic antifungal

78 activities, phenylpropanoids were found to inhibit drug efflux (data not shown). Therefore,

79 polyphenols are also expected to show this effect since they have a phenylpropanoid-like

80 structure.

82 isolated from the rhizomes of Curcuma longa, which is part of the ginger family

83 (Zingiberaceae). Curcumin has been reported to reverse multidrug resistance in human

84 colon carcinoma, human gastric carcinoma, and human osteosarcoma cell lines (Tang et 
87 Cdr1p and Cdr2p (Sharma et al. 2009).

antifungal model agent dodecanol on multidrug resistance in a wild-type strain of $S$. cerevisiae, which has an endogenous expression system of multidrug-efflux-related genes.

91 Namely, the study was performed without genetically manipulating the strain. Dodecanol was used because it shows a transient fungicidal action due to its efflux from fungal cells

93 (Fujita et al. 2017)

\section{Results and discussion}

\section{Effect of curcumin on the antifungal action of dodecanol against $S$. cerevisiae}

97 It has been reported that curcumin exhibits antifungal activity against Cryptococcus neoformans, C. albicans, Rhizoctonia solani, Phytophthora infestans, and Erysiphe graminis, but that its potency is quite weaker than that of antifungal agents on the market

100 (Moghadamtousi et al. 2014). Moreover, details of its mechanism of antifungal action are

101 poorly understood. Conversely, dodecanol is reported to show a rapid but temporal 
103 curcumin, dodecanol, and their combination on the growth of a wild-type strain of $S$.

104 cerevisiae based on measurements of colony forming units (CFU)(Fig. 2).

111 assay showed that $313 \mu \mathrm{M}$ curcumin did not affect proliferation of the yeast cells (Fig.

112 2). Furthermore, rapid reduction and restoration of cell viability were observed within 24

$113 \mathrm{~h}$ of exposure to $156 \mu \mathrm{M}$ dodecanol, indicating a transient fungicidal activity of the

114 alcohol. However, after $48 \mathrm{~h}$ of incubation, cell viability was restored to the control level.

115 These results suggest that curcumin and dodecanol as individual treatments do not

116 completely inhibit yeast growth for long periods. However, restoration of cell viability

117 was completely inhibited for $72 \mathrm{~h}$ when the cells were treated with $313 \mu \mathrm{M}$ curcumin and

$118156 \mu \mathrm{M}$ dodecanol concurrently. This suggests that curcumin sustained the temporary

119 fungicidal effect of dodecanol on S. cerevisiae. 
$121 P D R 3 \Delta$ and PDR5 (Fujita et al. 2017). Pdr5p is a major multidrug efflux pump and

122 Pdr3p is its transcription factor (MacPherson et al. 2006; Sipos and Kuchler 2006;

123 Yibmantasiri et al. 2014). This suggests that the intracellular dodecanol level was mainly

124 depleted by Pdr5p. However, this drug efflux system is possibly inhibited by curcumin to

125 maintain the intracellular dodecanol level, thereby inhibiting the growth of yeast cells.

126 Therefore, we examined the effect of curcumin on the activity of multidrug efflux pumps.

\section{Curcumin inhibits the efflux of R6G from $\boldsymbol{S}$. cerevisiae cells}

129 Generally, the fluorescent dye rhodamine $6 \mathrm{G}(\mathrm{R} 6 \mathrm{G})$ is passively incorporated into cells.

130 It is reported that Pdr5p is mainly responsible for the efflux of intracellular R6G (Egner

131 et al. 1998). In order to examine the effect of curcumin on the activity of multidrug efflux

132 pumps in R6G-prestained cells, the fluorescence derived from R6G in the supernatant of

133 the cell suspension was measured after the cells were treated with or without $312.5 \mu \mathrm{mol}$

$1341^{-1}$ curcumin. It was noted that the fluorescent spectra of curcumin and R6G overlapped (data not shown). Therefore, it is difficult to quantify R6G in the presence of curcumin. R6G 
137 and curcumin were separated by HPLC as shown in Fig. 3. R6G fluorescence in the

138 supernatants was measured every 20 min after adding glucose to measure the total activity

139 of ATP-dependent transporters, primarily Pdr5p (Mamnun et al. 2004; Paul and Moye-

140 Rowley 2014). When the yeast cells were not treated with curcumin, the fluorescence

141 intensity of R6G increased linearly as incubation time was increased up to $60 \mathrm{~min}$.

142 Conversely, when the cells were treated with $313 \mu \mathrm{mol} 1^{-1}$ curcumin, increase in

143 fluorescence intensity was apparently reduced (Fig. 4, left). This phenomenon is possibly

144 caused by a decrease in the total amount of intracellular R6G dependent on the

145 degradation of R6G. Therefore, we confirmed the intracellular R6G levels in the cells

146 treated with or without $313 \mu \mathrm{mol}^{-1}$ curcumin. The intracellular R6G level in the

147 curcumin-treated cells was $38 \%$ of that in untreated cells (Fig. 4, right), indicating the

148 intracellular accumulation of R6G induced by curcumin. These results suggest that

149 curcumin inhibits the total activity of multidrug efflux pumps.

150

151 Curcumin inhibits the expression of genes related to efflux pumps in the presence of

dodecanol

153 Curcumin suppresses the overexpression and function of the human multidrug resistance 
154 (MDR1) gene (P-glycoprotein), thereby reversing the multidrug-resistant phenotype

155 (Anuchapreeda et al. 2006; Choi et al. 2008; Neerati et al. 2013). Moreover, it dose-

156 dependently reduces MDR1-mediated drug efflux in multidrug-resistant cervical

157 carcinoma cells via direct interaction with MDR1 proteins (Anuchapreeda et al. 2002).

158 In addition, curcumin has been reported to regulate the mRNA expression of MDR1 by

159 inhibiting several signalling pathways involving phosphatidylinositol-4, 5-bisphosphate

160 3-kinase, Akt, and nuclear factor-kappa B (Choi et al. 2008; Rodrigues et al. 2016).

161 Human MDR1 proteins are ABC transporter proteins (Riordan et al. 1985;

162 Roninson et al. 1986; Gulshan and Moye-Rowley 2007). In contrast, the multidrug-

163 resistant phenotype of $S$. cerevisiae is responsible for pleiotropic resistance (Balzi and

164 Goffeau 1995). S. cerevisiae was reported to possess at least 16 ABC multidrug transport

165 proteins (Chinen et al. 2011). Although curcumin modulates drug efflux in S. cerevisiae

166 cells overexpressing the ABC transporters Cdr1p, Cdr2p, and Pdr5p (Sharma et al. 2009),

167 no synergistic antifungal effects against wild-type fungal strains without genetic

168 manipulation, such as a stress-inducible overexpression of multidrug efflux pump-related

169 genes, have been reported. 
171 SNQ2, YOR1, and YCF1) in S. cerevisiae, PDR5 1 was found to be hypersensitive to

172 dodecanol (Fujita et al. 2017). Thus, we measured the relative gene expression of PDR5

173 and its transcription factors PDR1 and PDR3 (Salin et al. 2008) in the cells treated with

174 dodecanol and curcumin or only curcumin. Pdr1p encoded by PDR1 responds to

175 intracellular stress signals, after which it promotes the transcription of PDR3 (Sipos and

176 Kuchler 2006; Ma and Liu 2010). Conversely, Pdr3p encoded by PDR3 regulates its

177 transcription and that of PDR5 (Sipos and Kuchler 2006; Ma and Liu 2010). It was noted

178 that the expression levels of PDR1, PDR3, and PDR5 were unaffected by curcumin (Fig.

179 5). Conversely, the expression levels of PDR1, PDR3, and PDR5 in the cells were

180 approximately 3.0-, 3.1-, and 6.3-fold, respectively, higher after treatment with $32 \mu \mathrm{M}$

181 dodecanol than they were without drug treatment. However, as a combined treatment,

182 curcumin and dodecanol reduced the expression levels of the genes compared to their

183 respective control levels. These results suggest that curcumin prevents dodecanol-

184 induced overexpression of PDR1, PDR3, and PDR5. This indicates that curcumin

185 possibly maintains the accumulation of dodecanol in the cells, thereby preventing the

186 restoration of cell viability. However, it is unclear whether curcumin directly affects the

187 transcription of $P D R 1, P D R 3$, and $P D R 5$, or other genes. 
189 curcumin (Fig. 4, left). Therefore, curcumin possibly inhibits the efflux activity of Pdr5p

190 due to direct interaction with the protein molecules of Pdr5p, degradation of Pdr5p, or

191 abnormality in localisation of Pdr5p, in addition to the restriction of PDR5 transcription. In the present study, curcumin and dodecanol showed a synergetic antifungal

193 activity against the nonpathogenic fungus $S$. cerevisiae. The human opportunistic

194 pathogen $C$. albicans possesses $C D R 1$ and $C D R 2$ genes as its primary multidrug pumps

195 (Sipos and Kuchler 2006). Cdr1p and Cdr2p are homologs of S. cerevisiae Pdr5p (Coste

196 et al.2006). Therefore, curcumin might be effective in potentiating the effect of antifungal

197 drugs that undergo efflux by Cdr1p and/or Cdr2p (Sanguinetti et al. 2015), which include

198 azoles (e.g., fluconazole).

199

Although curcumin and dodecanol exhibited synergistic antifungal activity against $S$. cerevisiae, curcumin must be further investigated for its clinical application since it has poor aqueous solubility. For instance, it is reported that microencapsulating curcumin improves its stability and solubility, as well as its antimicrobial effects against 
204 enterocolitica, Staphylococcus aureus, Bacillus subtilis, B. cereus, Aspergillus niger,

205 Penicillum notatum, and S. cerevisiae (Wang et al. 2009).

207 expression, thereby enhancing antifungal effects. Thus, curcumin potentially promotes

208 the efficacy of antifungals via its effects on $\mathrm{ABC}$ transporters in wild-type fungal strains.

\section{Materials and methods}

\section{Strain and culture conditions}

212 S. cerevisiae BY4741 and ATCC7754 were obtained from Yeast Knockout Collection

213 (Thermo Scientific Open Biosystems, Waltham, MA, USA) and American Type Culture

214 Collection (Manassas, VA, USA), respectively. The yeast cells were grown in $2.5 \%$ malt

215 extract broth (Oriental Yeast, Tokyo, Japan) for $16 \mathrm{~h}$ at $30^{\circ} \mathrm{C}$ without shaking prior to

216 performing the experiments.

\section{Chemicals}

$218 n$-Dodecanol was purchased from Kishida Chemical Co., Ltd. (Osaka, Japan). Curcumin

219 and $N, N$-dimethylformamide (DMF) were purchased from Wako Pure Chemicals (Osaka,

220 Japan). R6G was purchased from Sigma-Aldrich (St. Louis, MO, USA). $n$-Dodecanol and 
221 curcumin were diluted with DMF before use, whereas R6G was diluted with ethanol.

\section{Antifungal assay}

223 An antifungal assay was performed as previously described (Fujita and Kubo 2002; Nihei

224 et al.2004). Serial two-fold dilutions of the tested compounds, curcumin and dodecanol,

225 were prepared in DMF, after which $30 \mu 1$ of a 100 -fold concentrated solution was added

226 to $3 \mathrm{ml}$ of $2.5 \%$ malt extract broth in a test tube (diameter, $10 \mathrm{~mm}$ ). The yeast cells were

227 inoculated into the medium to obtain a final inoculum size of $10^{6} \mathrm{CFU} \mathrm{ml}^{-1}$. The cultures

228 were incubated without shaking for $48 \mathrm{~h}$, after which MIC was determined. MIC was

229 defined as the lowest concentration of a test compound that allowed for no visible

230 growth. After determining the MIC, an aliquot was withdrawn from each culture and

231 diluted 100 -fold with $2.5 \%$ malt extract broth. After $48 \mathrm{~h}$ of incubation, the minimum

232 fungicidal concentration was determined as the lowest concentration of a test compound

233 that did not allow for any recovery of yeast cells.

\section{Time-kill assay}

235 Yeast cells were grown overnight in $2.5 \%$ malt extract broth and diluted with the same

236 broth to obtain $1 \times 10^{6}$ cells $\mathrm{ml}^{-1}$. The cell suspensions were incubated at $30^{\circ} \mathrm{C}$ without

237 shaking in $2.5 \%$ malt extract broth containing dodecanol, curcumin, or their combination. 
238 Thereafter, the number of viable cells in each suspension was determined as CFU, using

$239 \quad 1.5 \%$ agar plates containing $1 \%$ yeast extract, $2 \%$ polypeptone, and $2 \%$ glucose. The agar

240 plates were incubated at $30^{\circ} \mathrm{C}$ for $48 \mathrm{~h}$ prior to counting CFU.

\section{$241 \quad$ RNA extraction}

242 Total RNA fractions were extracted using RNeasy Mini Kit (Qiagen, Hilden, Germany)

243 according to the manufacturer's instructions. The yeast cells treated with dodecanol

244 and/or curcumin were collected by centrifugation at $5,000 \times g$ for $10 \mathrm{~min}$, prior to cell

245 lysis with zymolyase. RNA was filtered out of each suspension using an RNA column

246 and treated with DNase. The RNA fractions were reverse-transcribed into cDNA using

247 ReverTra Ace (TOYOBO, Osaka, Japan).

\section{Reverse transcription-polymerase chain reaction (RT-PCR) analysis}

249 Gene expression was relatively quantified by RT-PCR in BY4741 cells treated with

250 dodecanol and/or curcumin in $2.5 \%$ malt extract broth with shaking at $30^{\circ} \mathrm{C}$ for $4 \mathrm{~h}$. Total

251 RNA was isolated from the cells using the RNeasy Mini Kit and 0.5-5.0 $\mu \mathrm{g}$ of it was used

252 for cDNA synthesis using ReverTra Ace. RT-PCR was conducted using Taq polymerase

253 (BioLabs, Ipswich, MA, USA), cDNA, and a thermal cycler (Applied Biosystems 2720;

254 Thermo Fisher Scientific, Waltham, MA, USA). The cycling parameters were 2 min at 
$25594^{\circ} \mathrm{C}$ and then 23 cycles of $30 \mathrm{~s}$ at $94^{\circ} \mathrm{C}, 30 \mathrm{~s}$ at $60^{\circ} \mathrm{C}, 1 \mathrm{~min}$ at $72^{\circ} \mathrm{C}$, and then $5 \mathrm{~min}$ at

$25672{ }^{\circ} \mathrm{C}$. The relative expression levels of PDR1, PDR3, and PDR5 genes were normalised

257 against those of the housekeeping gene $A C T 1$. The primers used in this study are listed in

258 Table S1.

259

Each amplified DNA sample was electrophoresed on 1\% agarose gel, stained

260 with GelRed (Biotium, Inc., Hayward, CA, USA), and visualised under UV light. The

261 relative expression levels of each gene were quantified using Fujifilm Multi Gauge

262 Version 2.1. Data have been expressed as mean \pm standard deviation of triplicate

263 determinations.

264 Efflux of R6G

265 Yeast cells from an overnight culture in $2.5 \%$ malt extract broth were centrifuged at 9,600

$266 \times g$ for $5 \mathrm{~min}$ at $27^{\circ} \mathrm{C}$. Next, the cells were harvested, washed twice with phosphate-

267 buffered saline (PBS), and resuspended in PBS. Thereafter, the cell suspension was

268 incubated with shaking at $30^{\circ} \mathrm{C}$ for $12 \mathrm{~h}$, centrifuged at $9,600 \times g$ for $5 \mathrm{~min}$ at $27^{\circ} \mathrm{C}$, and

269 resuspended in PBS to obtain a cell density of $5 \times 10^{8}$ cells $\mathrm{ml}^{-1}$. R6G $\left(10 \mu \mathrm{mol} \mathrm{l}^{-1}\right)$ was

270 added to the suspension, after which the cells were incubated for $60 \mathrm{~min}$ at $30^{\circ} \mathrm{C}$, washed,

271 and resuspended in PBS at $7.5 \times 10^{7}$ cells $\mathrm{ml}^{-1}$. Curcumin and $10 \mathrm{mmol}^{-1}$ glucose were 
272 then added to the suspension. Aliquots $(1 \mathrm{ml})$ of the suspension were withdrawn at

273 predetermined times and centrifuged at $2,000 \times g$ for $30 \mathrm{~s}$ at $27^{\circ} \mathrm{C}$ to obtain supernatant

274 for the assay of R6G efflux. After 60-min incubation with or without curcumin, the cells

275 were harvested by centrifugation, and lysed in $70 \%$ ethanol by 10 cycles of $6 \mathrm{~s}$ with $0.5-$

276 mm acid-washed glass beads using a bead beater (Bio Medical Science, Tokyo, Japan).

277 The suspensions were centrifuged and the cell-free extracts were then obtained for

278 determination of intracellular R6G level.

280 was measured by high-performance liquid chromatography (HPLC) using an ODS

281 column (5C18-MS-II; Nacalai Tesque, Kyoto, Japan). Isocratic elution was performed at

$28230^{\circ} \mathrm{C}$ with $50 \%$ acetonitrile containing $0.1 \%$ formic acid. The flow rate of the mobile

283 phase was set at $1.0 \mathrm{ml} \mathrm{min}{ }^{-1}$. Detection was performed using a fluorescence detector (FP-

284 1520S; JASCO, Tokyo, Japan) at excitation and emission wavelengths of 485 and 535

$285 \mathrm{~nm}$, respectively. A calibration curve was plotted for calculating the concentration of R6G

286 from its fluorescence intensity.

287 Statistical analysis

288 Statistical evaluation was performed using Student's $t$-test. $P$ values $<0.05$ indicated 
statistical significance.

290

\section{Acknowledgements}

292 This study was partly funded by the Japan Society for the Promotion of Science, Grants-

293 in-Aid for Scientific Research (C) 25460128 and 16K08299.

294

\section{Conflict of interest}

296 The authors have no conflict of interest to declare.

298 References

299 Anuchapreeda, S., Thanarattanakorn, P., Sittipreechacharn, S., Tima, S., Chanarat, P. and

300 Limtrakul, P. (2006) Inhibitory effect of curcumin on MDR1 gene expression in patient

301 leukemic cells. Arch Pharm Res 29, 866-873.

302

303 Anuchapreeda, S., Leechanachai, P., Smith, M.M., Ambudkar, S.V. and Limtrakul, P.N.

304 (2002) Modulation of P-glycoprotein expression and function by curcumin in multidrug-

resistant human KB cells. Biochem Pharmacol 64, 573-582. 
307 Balzi, E. and Goffeau, A. (1995) Yeast multidrug resistance: The PDR network. $J$ 308 Bioenerg Biomembr 27, 71-76.

309

310 Cannon, R.D., Lamping, E., Holmes, A.R., Niimi, K., Baret, P.V., Keniya, M.V., Tanabe,

311 K., Niimi, M., Goffeau, A. and Monk, B.C. (2009) Efflux-mediated antifungal drug 312 resistance. Clin Microbiol Rev 22, 291-321.

314 Chinen, T., Ota, Y., Nagumo, Y., Masumoto, H. and Usui, T. (2011) Construction of 315 multidrug-sensitive yeast with high sporulation efficiency. Biosci Biotechnol Biochem 75, $316 \quad 1588-1593$.

318 Choi, B.H., Kim, C.G., Lim, Y., Shin, S.Y. and Lee, Y.H. (2008) Curcumin down319 regulates the multidrug-resistance mdrlb gene by inhibiting the PI3K/Akt/NFkB pathway. Cancer Lett 259, 111-118. 
323 Bille, J. and Sanglard, D. (2006) A mutation in Tac1p, a transcription factor regulating

$324 C D R 1$ and $C D R 2$, is coupled with loss of heterozygosity at chromosome 5 to mediate

antifungal resistance in Candida albicans. Genetics 172, 2139-2156.

326

327 Egner, R., Rosenthal, F.E., Kralli, A., Sanglard, D. and Kuchler, K. (1998) Genetic 328 separation of FK506 susceptibility and drug transport in the yeast Pdr5 ATP-binding 329 cassette multidrug resistance transporter. Mol Biol Cell 9, 523-543.

330

331 Fairlamb, A.H., Gow, N.A., Matthews, K.R. and Waters, A.P. (2016) Drug resistance in 332 eukaryotic microorganisms. Nat Microbiol 1, 16092.

334 Fujita, K. and Kubo, I. (2002) Antifungal activity of octyl gallate. Int J Food Microbiol 335 79, 193-201. Fujita, K.I., Ishikura, T., Jono, Y., Yamaguchi, Y., Ogita, A., Kubo, I. and Tanaka, T.

338 (2017) Anethole potentiates dodecanol's fungicidal activity by reducing PDR5 expression in budding yeast. Biochim Biophys Acta 1861, 477-484. 
341 Ghannoum, M.A. and Rice, L.B. (1999) Antifungal agents: mode of action, mechanisms

342 of resistance, and correlation of these mechanisms with bacterial resistance. Clin

343 Microbiol Rev 12, 501-517.

344

345 Gonçalves, S.S., Souza, A.C.R., Chowdhary, A., Meis, J.F. and Colombo, A.L. (2016)

346 Epidemiology and molecular mechanisms of antifungal resistance in Candida and

347 Aspergillus. Mycoses 59, 198-219.

348

349 Gulshan, K. and Moye-Rowley, W.S. (2007) Multidrug resistance in fungi. Eukaryot Cell

350 6, 1933-1942.

351

352 Guo, X., Li, J., Wang, T., Liu, Z., Chen, X., Li, Y., Gu, Z., Mao, X., Guan, W. and Li, Y.

353 (2012) A mutation in intracellular loop 4 affects the drug-efflux activity of the yeast

354 multidrug resistance ABC transporter Pdr5p. PLoS One 7, e29520.

356 Katzmann, D.J., Burnett, P.E., Golin, J., Mahé, Y. and Moye-Rowley, W.S. (1994) 
357 Transcriptional control of the yeast PDR5 gene by the PDR3 gene product. Mol Cell Biol

358 14, 4653-4661.

359

360 Kubo, I., Fujita, K., Nihei, K. and Nihei, A. (2004) Antibacterial activity of akyl gallates

361 against Bacillus subtilis. J Agric Food Chem 52, 1072-1076.

362 Li, X.Z. and Nikaido, H. (2009) Efflux-mediated drug resistance in bacteria: an update.

363 Drugs 69, 1555-1623.

364

365 Lopes-Rodrigues, V., Sousa, E. and Vasconcelos, M.H. (2016) Curcumin as a modulator

366 of P-glycoprotein in cancer: challenges and perspectives. Pharmaceuticals (Basel) 9, 71.

367

368 Lu, W.D., Qin, Y., Yang, C., Li, L. and Fu, Z.X. (2013) Effect of curcumin on human

369 colon cancer multidrug resistance in vitro and in vivo. Clinics (Sao Paulo) 68, 694-701.

370

371 Ma, M., Liu, Z.L. (2010) Comparative transcriptome profiling analyses during the lag

372 phase uncover $Y A P 1, P D R 1, P D R 3, R P N 4$, and $H S F 1$ as key regulatory genes in genomic

373 adaptation to the lignocellulose derived inhibitor HMF for Saccharomyces cerevisiae. 
BMC Genomics 11, 660.

375

376

MacPherson, S., Larochelle, M. and Turcotte, B. (2006) A fungal family of transcriptional

377

regulators: the zinc cluster proteins. Microbiol Mol Biol Rev 70, 583-604.

378

379

Mamnun, Y.M., Schüller, C. and Kuchler, K. (2004) Expression regulation of the yeast

PDR5 ATP-binding cassette $(\mathrm{ABC})$ transporter suggests a role in cellular detoxification

381 during the exponential growth phase. FEBS Lett 559, 111-117.

382

383 Masiá Canuto, M. and Gutiérrez Rodero, F. (2002) Antifungal drug resistance to azoles

384 and polyenes. Lancet Infect Dis 2, 550-563.

385

386 Miceli, M.H., Díaz, J.A. and Lee, S.A. (2011) Emerging opportunistic yeast infections.

Lancet Infect Dis 11, 142-151.

388

389 Moghadamtousi, S.Z., Kadir, H.A., Hassandarvish, P., Tajik, H., Abubakar, S. and Zandi,

390 K. (2014) A review on antibacterial, antiviral, and antifungal activity of curcumin. Biomed 
393 Neerati, P., Sudhakar, Y.A. and Kanwar, J.R. (2013) Curcumin regulates colon cancer by 394 inhibiting P-glycoprotein in in-situ cancerous colon perfusion rat model. J Cancer Sci 395 Ther 5, 313-319.

396

397 Paul, S. and Moye-Rowley, W.S. (2014) Multidrug resistance in fungi: regulation of 398 transporter-encoding gene expression. Front Physiol 5, 143.

400 Polak, A. and Hartman, P.G. (1991) Antifungal chemotherapy--are we winning? Prog $401 \quad$ Drug Res 37, 181-269.

402

403 Riordan, J.R., Deuchars, K., Kartner, N., Alon, N., Trent, J. and Ling, V. (1985)

404 Amplification of P-glycoprotein genes in multidrug-resistant mammalian cell lines.

$405 \quad$ Nature 316, 817-819.

406

407 Roninson, I.B., Chin, J.E., Choi, K.G., Gros, P., Housman, D.E., Fojo, A., Shen, D.W., 
408 Gottesman, M.M. and Pastan, I. (1986) Isolation of human mdr DNA sequences amplified

409 in multidrug-resistant KB carcinoma cells. Proc Natl Acad Sci U S A 83, 4538-4542.

410

411 Salin, H., Fardeau, V., Piccini, E., Lelandais, G., Tanty, V., Lemoine, S., Jacq, C. and

412 Devaux, F. (2008) Structure and properties of transcriptional networks driving selenite

413 stress response in yeasts. BMC Genomics 9, 333.

414

415 Sanguinetti, M., Posteraro, B. and Lass-Flörl, C. (2015) Antifungal drug resistance among

416 Candida species: mechanisms and clinical impact. Mycoses 58 (Suppl 2), 2-13.

418 Sharma, M., Manoharlal, R., Shukla, S., Puri, N., Prasad, T., Ambudkar, S.V. and Prasad,

419 R. (2009) Curcumin modulates efflux mediated by yeast ABC multidrug transporters and

420 is synergistic with antifungals. Antimicrob Agents Chemother 53, 3256-3265.

421

422 Si, M., Zhao, J., Li, X., Tian, J.G., Li, Y.G. and Li, J.M. (2013) Reversion effects of 423 curcumin on multidrug resistance of MNNG/HOS human osteosarcoma cells in vitro and

424 in vivo through regulation of P-glycoprotein. Chin Med J (Engl) 126, 4116-4123. 
426 Sipos, G. and Kuchler, K. (2006) Fungal ATP-binding cassette (ABC) transporters in 427 drug resistance \& detoxification. Curr Drug Targets 7, 471-481.

428

429 Tang, X.Q., Bi, H., Feng, J.Q. and Cao, J.G. (2005) Effect of curcumin on multidrug 430 resistance in resistant human gastric carcinoma cell line SGC7901/VCR. Acta 431 Pharmacol Sin 26, 1009-1016.

432

433 Thakur, J.K., Arthanari, H., Yang, F., Pan, S.J., Fan, X., Breger, J., Frueh, D.P., Gulshan, 434 K., Li, D.K., Mylonakis, E., Struhl, K., Moye-Rowley, W.S., Cormack, B.P., Wagner, G. 435 and Näär, A.M. (2008) A nuclear receptor-like pathway regulating multidrug resistance 436 in fungi. Nature 452, 604-609.

437

438 Yibmantasiri, P., Bircham, P.W., Maass, D.R., Bellows, D.S. and Atkinson, P.H. (2014)

439 Networks of genes modulating the pleiotropic drug response in Saccharomyces cerevisiae. Mol Biosyst 10, 128-137. 
442 Wang, Y., Lu, Z., Wu, H. and Lv, F. (2009) Study on the antibiotic activity of

443 microcapsule curcumin against foodborne pathogens. Int J Food Microbiol 136, 71-74.

444

445 Supporting information

446 Additional Supporting Information may be found in the online version of this article:

447

448 Table S1. Primer sets for RT-PCR analysis

449

$450 \quad$ Figure legends

451 Figure 1 Chemical structures of curcumin, trans-anethole, and $n$-dodecanol.

452

453 Figure 2 Effect of curcumin on dodecanol-induced temporary death of S. cerevisiae

454 ATCC7754.

455 The yeast cells were grown in $2.5 \%$ malt extract broth at $30^{\circ} \mathrm{C}$. The following drugs were

456 then added to the culture: $156 \mu \mathrm{mol} \mathrm{l}^{-1}$ dodecanol (घ), $312.5 \mu \mathrm{mol} \mathrm{l^{-1 }}$ curcumin (o), and

$457156 \mu \mathrm{mol} \mathrm{l}^{-1}$ dodecanol $+312.5 \mu \mathrm{mol} \mathrm{l}^{-1}$ curcumin $(\square)$. The closed circle $(\bullet)$ denotes no

458 drug treatment. Data are expressed as mean \pm standard deviation $(n=3)$. 
460 Figure 3 Separation of R6G from curcumin by HPLC.

461 HPLC was performed using the ODS column 5C 18 -MS- II . Isocratic elution was

462 performed at $30^{\circ} \mathrm{C}$ using $\mathrm{H}_{2} \mathrm{O}$ acetonitrile $(1: 1, \mathrm{v} / \mathrm{v})$ containing $0.1 \%$ formic acid as the

463 mobile phase. The flow rate of the mobile phase was set at $1.0 \mathrm{ml} \mathrm{min}^{-1}$. Detection was

464 carried out at excitation and emission wavelengths of 485 and $535 \mathrm{~nm}$, respectively.

466 Figure 4 Effect of curcumin on R6G efflux and intracellular level of R6G.

467 R6G efflux (left). S. cerevisiae ATCC7754 cells were incubated without shaking at $30^{\circ} \mathrm{C}$

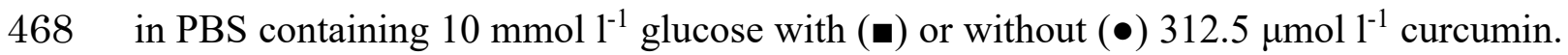

469 Fluorescence intensity of the supernatant was determined by HPLC. Data have been

470 expressed as mean \pm standard deviation $(\mathrm{n}=3)$. Intracellular level of R6G (right). $S$.

471 cerevisiae ATCC7754 cells were incubated without shaking at $30^{\circ} \mathrm{C}$ for $60 \mathrm{~min}$ in PBS

472 containing $10 \mathrm{mmol}^{-1}$ glucose with or without $312.5 \mu \mathrm{mol} \mathrm{l}^{-1}$ curcumin. After incubation,

473 fluorescence intensity in cell-free extracts was determined by HPLC. Data are expressed

474 as mean \pm standard deviation $(\mathrm{n}=3)$. 
476 Figure 5 Expression levels of $P D R 1, P D R 3$, and $P D R 5$ relative to that of $A C T 1$.

477 S. cerevisiae BY4741 cells were incubated in $2.5 \%$ malt extract broth containing 312.5

$478 \mu \mathrm{mol} \mathrm{l}^{-1}$ curcumin and/or $32 \mu \mathrm{mol} \mathrm{l^{-1 }}$ dodecanol. Total RNA was extracted for RT-PCR

479 analysis. Data are expressed as mean \pm standard deviation $(\mathrm{n}=3) .{ }^{*}$ indicates $p<0.05$. 
<smiles>COc1cc(/C=C/C(=O)CC(=O)/C=C/c2ccc(O)c(OC)c2)ccc1O</smiles>

Curcumin

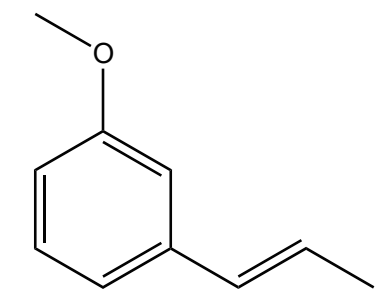

trans-Anethole<smiles>CCCCCCCCCCCCO</smiles>

\section{$n$-Dodecanol}

Figure 1. Yamawaki et al. 


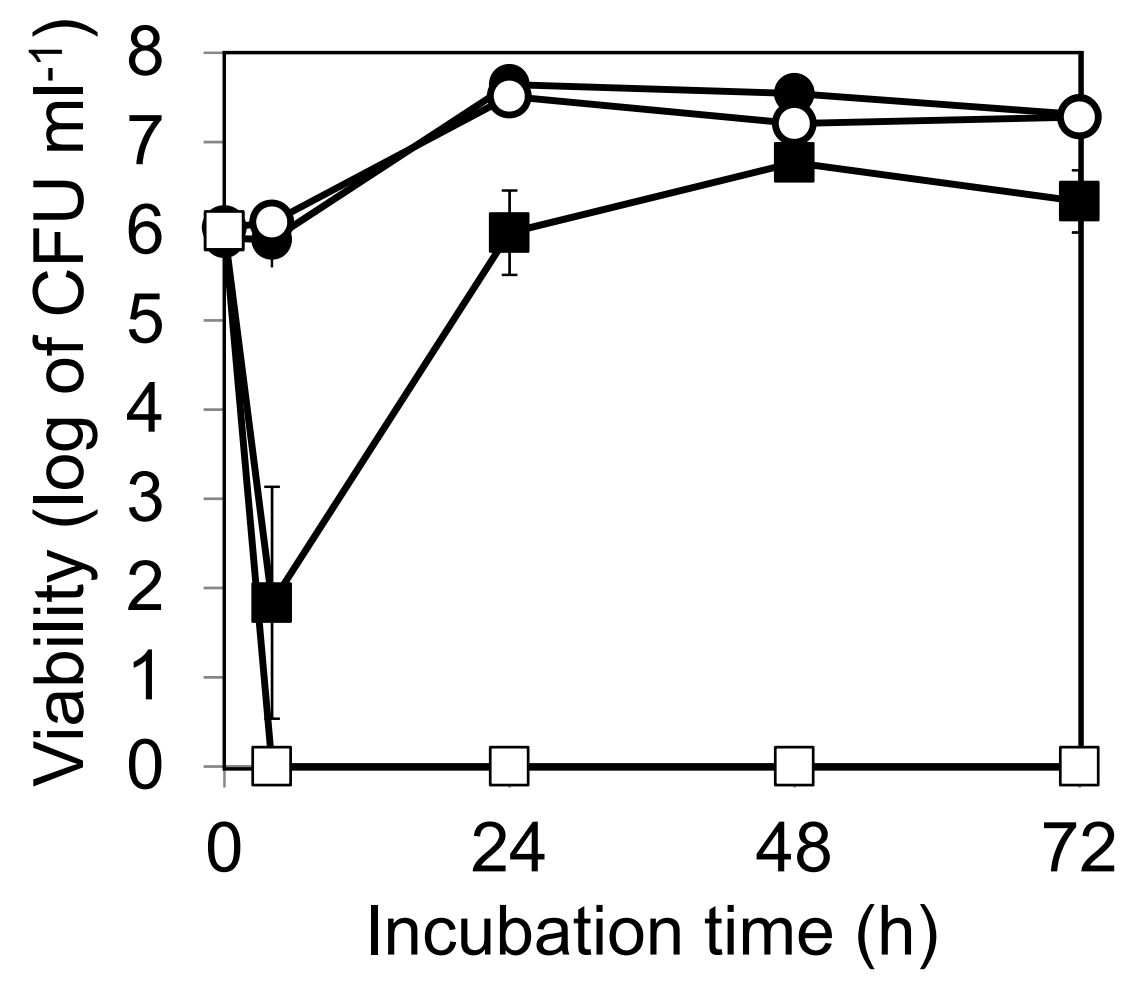

Figure 2. Yamawaki et al. 


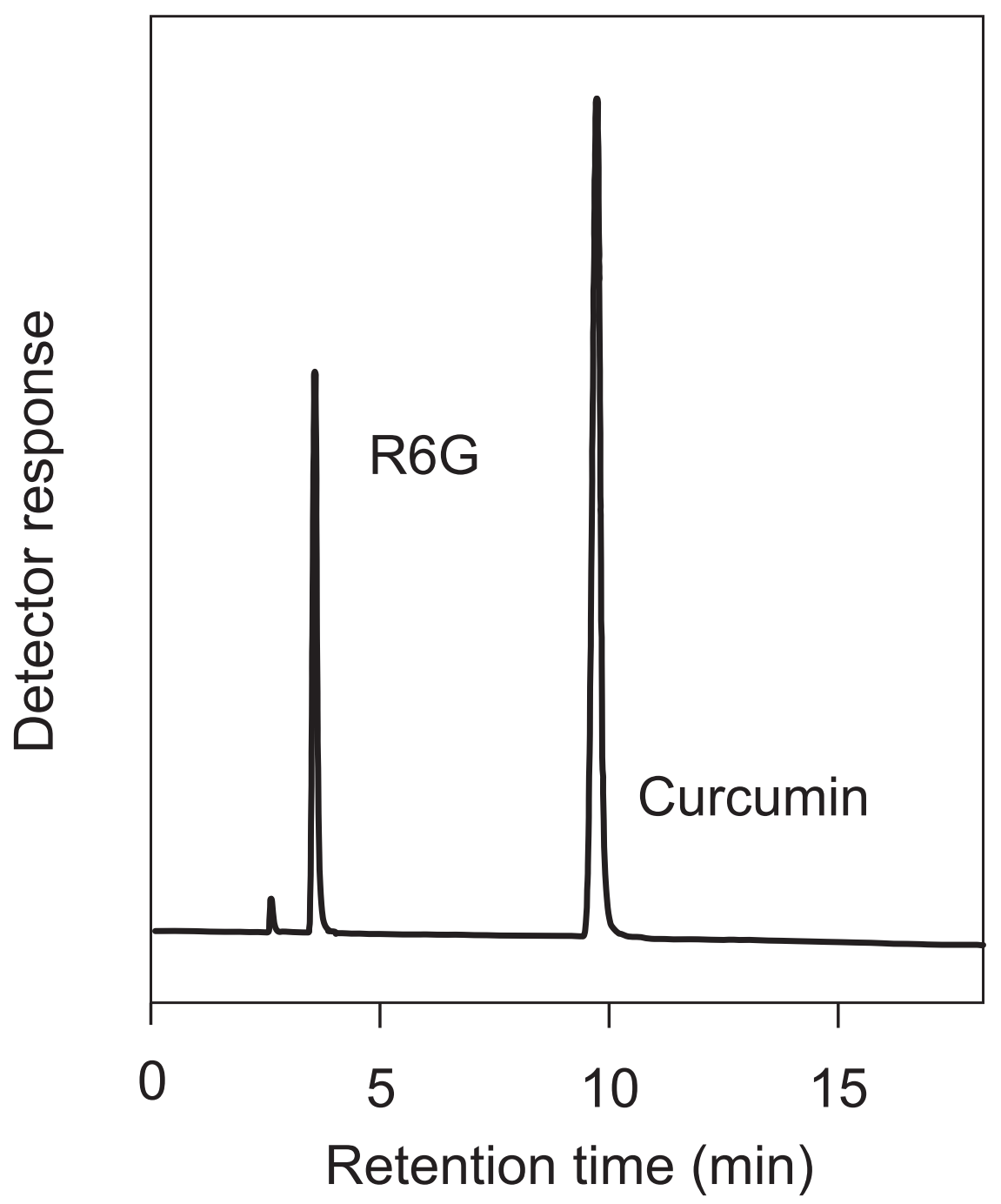

Figure 3. Yamawaki et al. 

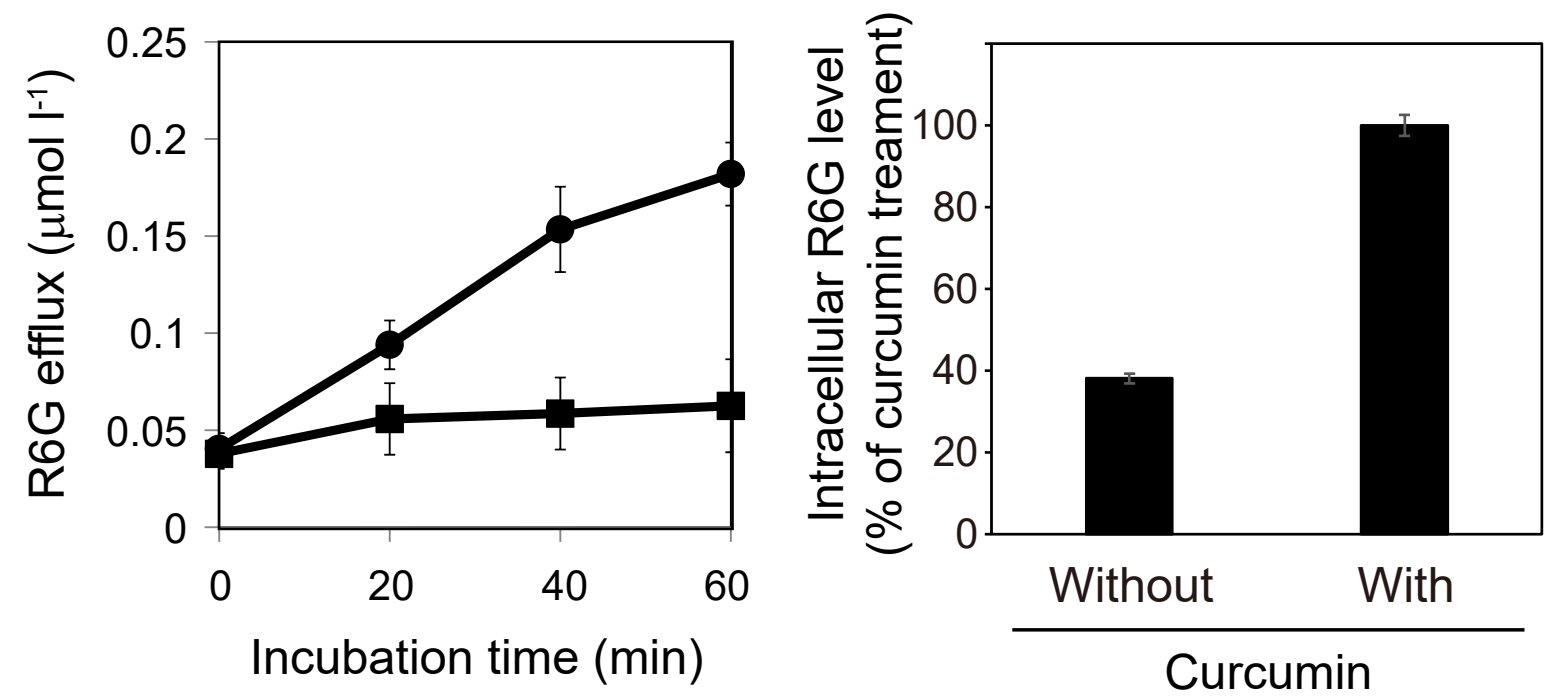

Figure 4. Yamawaki et al. 


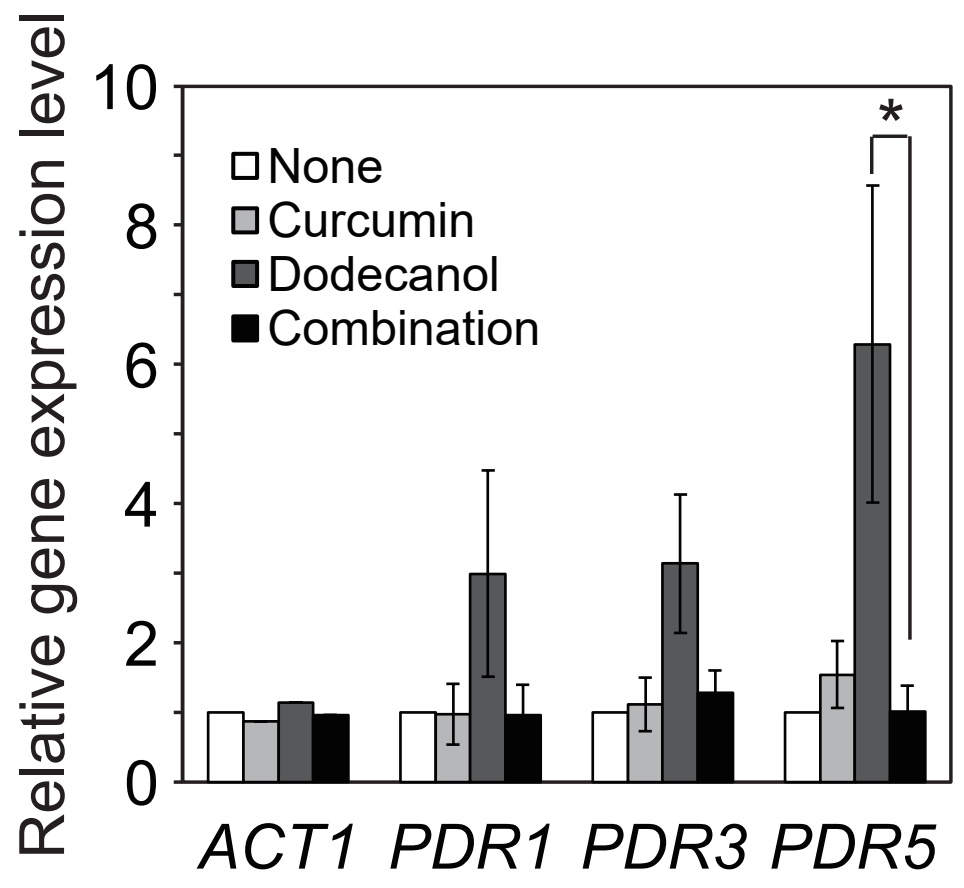

Figure 5. Yamawaki et al. 